\title{
Sustainable Coastal Tourism Policy Selection and Local Resident Satisfaction Assessment
}

\author{
Kuo-Yan Wang ${ }^{1, *}$ Jing $\mathrm{Yu}^{2}$ Chia-Yang Ning ${ }^{3}$ \\ 1,2,3 School of Economics and Management, Guangdong University of Petrochemical Technology, Maoming 525000, \\ China \\ *Corresponding author. Email: kywang@gdupt.edu.cn
}

\begin{abstract}
Coastal tourism, especially in the seaside township, has rapidly developed in the recent years. In addition to fishing industry, the development of tourism activities has become an income-generating method for local economy. This empirical study illustrates how a coastal township selects an appropriate tourism development solution using a simple group decision making method to replace the use of the traditional Delphi method or public hearing. The attitudes of the residents were surveyed in regards towards the costal tourism stimulus package implemented for half of a year. The discussions derived from the results can be used as a reference to upgrade the effectiveness of sustainable coastal tourism and regional economic development at the township level, as well as to properly respond to the needs of residents.
\end{abstract}

Keywords: Coastal tourism, Resident satisfaction, Solution assessment, Decision-making process

\section{INTRODUCTION}

Marine and coastal tourism are both among the oldest forms of tourism and the largest segment of the tourism industry. In addition, coastal and marine tourism is also the most important and fastest growing economic activity occurring in the sea [1]. Marine and coastal tourism as one of the largest segments of the maritime economy sector, as well as the largest component of the tourism industry, the development will not only generate economic growth but also ensure ecological and social sustainability. In addition, the concept of ecotourism also offers a tourism activity that prioritizes aspects of improving the welfare of the community [2].

Coastal/marine tourism development is mainly driven by governments at the national and/or local level. These are accompanied by investment in infrastructure to support development which is financed through both public institutions and private investors that support local economics [3]. The government usually has several ways to improve the welfare of fishermen in other sectors than the fisheries; one of them is connecting between fishermen, coastal and tourism [4]. However, the relational approaches to economic development are gaining ground as a significant issue, although in the coastal tourism development, their potential is only just becoming recognized [5].
As such, this empirical study attempts to reveal the current factors at work in a costal township tourism solution selection. This study introduces an easy-to-use, time-saving multiple-criteria decision-making method (MCDM) to the process of selecting which administrative works the local government should focus on. Subsequently, we surveyed the inhabitants of a coastal town, inquiring about their satisfaction with the new policy. The survey results yielded numerous implications.

The purpose of this township case study is to address the optimal local coastal tourism development policymaking system. Practical public administrative decisionmaking or problem-solving follows the "plan, do, check, and action" (PDCA) management cycle, which can be easily understood and applied by any organization [6]. The technique for order preference by similarity to ideal solution (TOPSIS) was utilized in this study. We then performed a comparative analysis of resident satisfaction survey results from the case township and other highly homogeneous coastal townships where the new policy was not implemented.

The remainder of this paper is organized as follows. The following section briefly presents the TOPSIS method to deal with the multiple-attribute, decisionmaking problem of the local administration issue. Then, the TOPSIS method is implemented to decide the new coastal tourism development solution, wherein 
descriptive statistical analysis is used to understand the differences of resident satisfaction within the neighbouring coastal townships in terms of the decision to push or not to push the new policy. Subsequently, the results revealed from the survey will be used to discuss this phenomenon. Conclusions are finally drawn in the final section.

\section{METHODOLOGY}

As a decision-making technique, the Delphi method is commonly used in a diverse range of applications, such as political, economic, social, and technological. The Delphi method can be defined as a "structural expert group communication process for solving decisionmaking problems" [7]. In a panel discussion, each participant of the group shares his/her own opinion, knowledge, or experiences. This method allows spontaneous processes to proceed in a defined direction through several meetings and surveys. This method results in a viable option rather than the 'best' or 'optimal' solution. However, because of its requirement for multiple discussions, the Delphi method is rather time-consuming. The Delphi method is also plagued by problems of dubious forecast accuracy [8]. It is vital that policy planning take a holistic approach, because when too much attention is given to specific details, it can be easy to lose sight of what is important. The Delphi method decision-making process excessively focuses on 'definitely viable option' acquisition.

With reference to Hwang and Yoon [9], the TOPSIS method is presented in Chen and Hwang [10](1992). The basic principle is that the chosen alternative should have the shortest distance from the ideal solution and the farthest distance from the negative-ideal solution. The TOPSIS procedure consists of the following six steps:

(1) Calculate the normalized decision matrix. The normalized value $\mathrm{r}_{\mathrm{ij}}$ is calculated as

$$
\mathrm{r}_{\mathrm{ij}=} f_{i j} / \sum_{j=1}^{j} f_{i j}^{2}, j=1, \ldots, J ; i=1, \ldots n .
$$

(2) Calculate the weighted normalized decision matrix. The weighted normalized value $\mathrm{v}_{\mathrm{ij}}$ is calculated as

$$
\mathrm{v}_{i j}=w_{i} r_{i j}, j=1, \ldots, J ; i=1, \ldots . n .
$$

where $w_{i}$ is the weight of the $i_{\text {th }}$ attribute or criterion and $\mathrm{w}_{\mathrm{i}}=1$.

(3) Determine the ideal and negative-ideal solution.

$$
\begin{aligned}
& A^{*}=\left\{\mathrm{v}_{1}{ }^{*}, \ldots, v_{n}{ }^{*}\right\} \\
& =\left\{\left(j \max v_{i j} \mid i \in i\right),\left(j \min v_{i j} \mid i \in I\right)\right\},
\end{aligned}
$$

$$
\begin{aligned}
& A^{*}=\left\{\mathrm{v}_{1}^{-}, \ldots, v_{n}^{-}\right\} \\
& =\left\{\left(j \min v_{i j} \mid i \in i\right),\left(j \min v_{i j} \mid i \in I\right)\right\},
\end{aligned}
$$

(3)

(4) Calculate the separation measures using the ndimensional Euclidean distance. The separation of each alternative from the ideal solution is given as

$$
D_{j}^{*}=\sqrt{\sum_{i=1}^{n}\left(v_{i j}-v_{\mathrm{i}}^{*}\right)^{2}}, j=1, \ldots, J .
$$

Similarly, the separation from the negative-ideal solution is given as

$$
D_{j}^{-}=\sqrt{\sum_{i=1}^{n}\left(v_{i j}-v_{\mathrm{i}}^{-}\right)^{2}}, j=1, \ldots, J .
$$

(5) Calculate the relative closeness to the ideal solution. The relative closeness of the alternative $a_{j}$ with respect to $A^{*}$ is defined as

$$
\mathrm{c}_{j}^{*}=\frac{D_{j}^{-}}{\left(D_{j}^{*}+D_{j}^{-}\right)}, j=1, \ldots, J .
$$

(6) Finally, rank the preference order.

\section{AN EMPIRICAL CASE}

\subsection{Applying TOPSIS for Optimal Sustainable Tourism Policy Selection}

Township B is a coastal town with more than 20 thousand residents, the main economic source is fishery. Because of a serious aging population problem, Township $\mathrm{B}$ management is required to suggest the economic stimulus package as a measure of slowing down the trend of young population outflow. Through numerous discussions, the management of Township B proposed four options of tourism development policy according to its rich coastal resources: increasing seaside amuse parks, introducing marine biology aquarium, expanding seafood market scale, or planning a marine ecological scenic area. Here, the experts and scholars make a final selection based on the views of the financial status and the expected satisfaction of voters of Township B. The data of each option were collected from the township office public information depending on the available fiscal space and expansionary fiscal policy. In evaluating each criteria weight of this primary stage, the relevant decision-making experts who participated were civil servants from the financial sector, elected representatives, and policymaking researchers. 
The experts assessed the subjectively relative importance for each of the criterion, a comprehensive interview was conducted with the pair-wise relative weighting questionnaire. The data shows that what is expected directly benefiting the residents is the most important criterion in evaluating the proposed new policy selection and can be explained by the attitude of citizens towards the incumbent township management performance. In addition, the implementation of new policy must consider the expected budget disbursement, signifying that the governmental finance status absolutely determines the choice of experts.

For determining the ideal and negative-ideal solution, the next is utilized by Equation (2) and (3), the results illustrated that $\mathrm{A}^{*}=\{0.068,0.088,0.089,0.009,0.014$, $0.031\} ; \mathrm{A}-=\{0.025,0.011,0.002,0.052,0.059,0.083\}$. Subsequently, we employed Equation (4) and (5) to calculate the separation of each alternative solution from the ideal solution.

The obtained TOPSIS ranking lists by Equation (6) indicated that the expanding seafood market scale at the township B is the optimal solution for developing local tourism policy $(0.671)$, then introduce marine biology aquarium is the second (0.479), increase seaside amuse park $(0.451)$, the least optimal solution is planning a marine scenic area (0.294).

\subsection{Descriptive Analysis Results}

In order to compare the differences in the local inhabitant satisfaction among neighbouring coastal towns where the new tourism development solution was either implemented or not, after half a year of expanded seafood market have completed and reopened of Township B on February 1, 2020, the pre-test stage has conducted by person on July 15 to July 22, each subdimension was generated by the opinions of respondents. Subsequently, the researchers surveyed the residents of Townships A, B, and C from August 1 to August 15 in 2020 under the similar fishery-based coastal area. Unlike Township B, Townships A and C did not have the new economic stimulus policy introduced. During this period, this study employed cluster sampling that sampled the residents of three townships who were randomly chosen to participate in this stage. A total of 804 questionnaires were issued and conducted in person. The survey ruled out respondents who were unwilling to answer and invalid responses, leaving 756 valid interviewees $(\mathrm{n}=$ 756 , approximately $94 \%$ ) to be used in this study. The administrative performances of the incumbents of Township B management were designed with four components: administrative satisfaction, public attention, local economic development, and confidence in future development. This survey also employed the Likert 1-to5 rating scale $(1=$ strongly disagree to $5=$ strongly agree). The questionnaire construction fully considered internal consistencies for each survey item and prevented reliability and validity less than the normal value (Cronbach's alpha value $=0.7$ ). The $\mathrm{KMO}$ value is 0.24 , and the Bartlett test is significant ( $\mathrm{p}<0.001)$ in this survey. Each item reflected the list of selected topics and was significantly distributed different at $5 \%$.

According to the result, Township B is prior to Townships $\mathrm{A}$ and $\mathrm{C}$ in regards to assessment of the four dimensions. Administrative satisfaction is the most recognized by respondents of Township B (79\%). Although relatively significant, it is worth noting that local construction is lower than other dimensions (68\%).

\section{DISCUSSION AND CONCLUSION}

In Township B, the original seafood market only existed as a wholesale market. After renovation and enlarged operations, the new market combines wholesale, retail and catering and other related industries, becoming a successful option to fully integrate local characteristics to develop a sustainable economy and initiate tourism industry. An otherwise unremarkable coastal town has become a popular tourist attraction. Expanding seafood market scale provides an opportunity to develop more economically and environmentally sound investments and businesses, utilize natural resources more efficiently and less environmentally, produces more efficient and resource symbiosis systems, produces greater products and economic value, increase labour absorption, and provide an opportunity to benefit each contributor's fairness. At the same time, it can also reduce dependence on the financial aspects of the superior government. Apparently, the survey revealed that increase in economic opportunities as an accelerator to retain young talents, simultaneously it can also promote the activation of the local economy and achieve the goal of sustainable development.

This study sought to consider, through an exploratory case study, the TOPSIS method as an essential role of township level sustainable tourism development proposal in terms of multiple group decision-making by the expert, scholar, and township representative. Despite the cultural and geographical differences, this study discussed the new option of Expanding seafood market scale, which can be a useful reference for township managements and aid in the economic situation of residents. Results of the survey showed that the town resident is satisfied with the newly implemented policy. In addition, numerous implications derived from the results illustrated also explain active regional economy measures. Future research may engage in a similar study of helping the improvement of coastal towns in poor economic conditions. These issues are worthy of further exploration and discussion.

\section{AUTHORS' CONTRIBUTIONS}

All authors contribute the whole process of this study. 


\section{ACKNOWLEDGMENTS}

The authors would like to thank Guangdong University of Petrochemical Technology for the funding.

\section{REFERENCES}

[1] F. Kurniawan, L. Adrianto, D.G. Bengen, L. B. Prasetyo, Vulnerability assessment of small islands to tourism: The case of the Marine Tourism Park of the Gili Matra Islands, Indonesia. Global Ecology and Conservation, 6, 2016, pp. 308-326.

[2] D. Tegar, R. O. S. Gurning, Development of marine and coastal tourism based on blue economy. International Journal of Marine Engineering Innovation and Research, 2, 2018, pp. 128-132.

[3] M. Honey, D. Krantz, Global trends in coastal tourism. Center on Ecotourism and Sustainable Development, 2007.

[4] E. Sukmayeti, A Social Mapping of Fishermen Resource and Accessibility for Coastal Tourism Development Policy. Society, 7, 2019, pp. 116-134.

[5] S. A. Clavé, J. Wilson, The evolution of coastal tourism destinations: A path plasticity perspective on tourism urbanisation. Journal of Sustainable Tourism, 25, 2017, pp. 96-112.

[6] A.S. Silva, C. F., Medeiros, R. K.Vieira, Cleaner Production and PDCA cycle: Practical application for reducing the Cans Loss Index in a beverage company. Journal of Cleaner Production, 150, 2017, pp. 324-338.

[7] J. Pariès J., J. Wreathall, J. Resilience engineering in practice: a guidebook. CRC Press, 2017.

[8] Y. Baruch, N. Szücs, N., H. Gunz, Career studies in search of theory: The rise and rise of concepts. Career Development International, 2015.

[9] C. L. Hwang, C.L. K. Yoon, K., Multiple Attribute Decision Making - Methods and Applications. Springer: New York, USA, 1981.

[10] S. J. Chen, C. L. Hwang, Fuzzy Multiple Attribute Decision Making: Methods and Applications. Springer-Verlag: Berlin, Germany, 1992. 